cases of hysteria which for time simulate! trismus, with this difference, however-they are accompanied with insensibility. This may continue for a cunsiderable while, and then pass of as if nuihing had happened except general langunr fion iho previous excitement. Here, then, ate three diseases, viz., epilepsy, cloorea, and hysteria, in which the nerves are con iessedly involve", and yet tow differcni from the disease under consilcration. It is most prowable blat the trigcminus or fifth pair of nerves, ai lenot its maxillary branches, are chicfly afícried in irismus; bui why they should be afiected unig transientiy in some insiances, and permanenty, and for the most yest faiciliy, in another, is past finding out. Whether the trigeminus be affected primariiy in tristans, and unly secouciarily on by sympatily inmon the ganglicnic system in the other diseases, is matter of mere specuidition, and I. shaii thereiore not pursuc the subjeci furiber.

Wiin regard to the treatrnent of ihis formidable disease I have nothing new to "fier, nor is it probabie the meihodus medendi will be improved until the nature of the disease be better understoud; be the case, since anatom now seems to have done its best; for we have only to look at Swan's beautiful and splendid delineations, and we may almost say, nothing remains to be done. As to the trammatic species, I shall say nothing. Our military surgical writers, such as $M^{\circ}$ Grigor, Hennen, Guthrie, \&c., candidly confess they cannot help us, and almost with one voice proclaim its intrictable natue. As to the jdiojathic, I am inclined to the opinion of $\mathrm{Dr}$. Tlamiltom, on purgatives, that the alimeniary canal is most concerned. Tha tiree cases he wentions are rather slight attacks, but by directing his attention to the sturmach aud borvels he was successful in their treatmont. In the case of the Rev. J. M. C. there had been previous costiveness, and the bowels were very dificult to be moved, and therefore we did not waste time by trying a great variety of remedies, which might have interfered with the clief object in view; indeed, foriyeight hours did not allow of much variety of treatment. Therefure, purgatives, and purgative enemala, bleeding, blistering, with opium and calomel, all the best ancispasmodics, were our chiof remeuies. The hot bath was not had recourse to, because, in this instance, where it was dificult to keep the patient sill, and he was frequently getting in and out of bed, it might have done more harm than good, especially as uuder the most favourable circumsiances it has been of littls avail, and some authors have thought it has done harm. On a review of this inieresting case, the course pursued, in the present state of our knowledge of therapeutics, was that most likely to have succeeded, and we have only to regret that our efforts have been unavailing.

\section{FURTHER OBSERVATIONS ON TRAUMATIC TETANUS.}

\section{To ithe Editor of The Lancet.}

Sin,-The accompanying remarks form a contimuation of those on tranmatic tetanus, at page 398 of The LANCET, for Dec. 18. I have the honour to remain, Sir, your obediení servant,

James B. Thompson, A.B., M.D.

33, Upper Gower-street,

Dec. 20, 1841.

The case of Sullivan difiers in one material point from cases of traumatic tetanus in general, uamely, in the suduenriess of the aggra. vated and fatal symptoms. It is a peculiarity in this disease, well worthy of notice, in a jricticai point of view, that it does not present itself at the early inflammatory, suppurative, or sloughing stages of a wound or injury, bui more frequently at a very lemote period, when the part injured may have healed over, and when the surgeon may have cunsidered his patient as couvalescent-or if all bospital patient, may be about to discharge him or her. In illustration of this peculiarity in tetauus, I may be permitted to add the following case, which occurred about seven years ago:-

A young man, about nineteen years of age, of nerrous temperament, but otherwise goud general health, a stable-boy at an hotel, received, while in the act of grooming a horse, a kick in the left knee; the cock of the shoe laid upen the capsule of the joint, and lacerated the inieguments. Severe infarimaiory symptoms supervened, but by aciive antiphlogistic remedies, and attention to the getieral constitution, these acute symptoms were subdued, and the round was lealed over in about the fifth week, when it was thunght desirable io recom:uend the patient $t$, go into the country for the benefit of his general health. But just the day but ote previous to his intended departure, he complained of being unwell, and rather resiless for the few nights before. He nur complained of stiftness in the neck, and from this period all the symptoms previously alludad to began to present thernselves. He got anodynes with morphia at night. I prefer the muriate of morphia in these cases. Mercury was used, by friction, along the spine, the inside of the thighs, and in the axilla, with small and frequently-repeated doses of calomel with opium, to prevent its passing off by the bowels, besides its own sedative efiect : camphor mixture, with the aromatic spirits of ammonia, occasionally. This treatment was pursued for some ten or twelve days, when the tetanic tendency seemed gradually to disappear. The patient was discharged quite convalescent in about a week after all medicines had ceased to be 
given. He did not seem to suffer any inconvenience from the active treatment pursued, as some surgeons seem to suppose such patients always do.

The period at which this affection generally presents itself, varies from a few days to ten, fifteen, and twenty-one days, and from four to six weels, or even to remoter periods. However, I am disposed to look rather favourably on a case going beyond the third week; at least I am inclined to think that the remuter the period the rnore mild and modified will be the atiack-indeed sarety fatal, if actively treated at 6ist.

As to the canses of this disease, there are a great variety, and some are of a very trivial character. It has been Inown to occur in a negro rom the lash of a whip. Pieces of glass, woorl, nails, pins, \&c., sticking in the hands or soles of the feet, or under the finger or toe-nails, have producerl this affection. The more aggravated exciling causes are, vicissitudes of temperature, injuries or lacerations of nervons or tendinous structures, punctured wounds, irritating substances in the stomach and intestinal canal.

I have seen tetanus in a modified form in a lunatic, proving that aifections of the mind predispose to this disease. I have also seen it in persons where the autopsies proved that abnormal depositions, or growths of a bony or cartilaginous structure, gave rise to this affection, particularly when these foreign bodies (if I may be allowed to call them so), by their presence and consequent pressure on the brain and spinal marrow, operated, no doubt, as a proximate cause in the production of the modified tetanic symptoms which exhibited themselves during the lifetime of these patients. As to the mode of treatment, it no doubt must vary according to the circumstances of the case, and the previous history of the patient. It is advisable to remove as early as possible the obvious exciting cause; next to this, I believe that the treatment pursued in the preceding case will be found to be the most generally resorted to, and from what I have seen ur read has been found to have been the most successful. Tobacco enemata are recommended, and may no doubt be found useful; but as for the cold bath, or douche, I have seen it prejudicial, and it is always unpleasant to the patient.

Our object should be to allay the generally-excited state of the brain and norvous system; and in carrying this view into effect, we must often commence by exciting, as it were, a new and powerful action, as if to supersede the primary or diseased one. This is, I apprehend, the view with which mercury, tobacco, musk, camphor, and opium, with other active antispasmodics, are so generally recommended. In cases of punctured wounds producing this disease, it is desirable to dilate freely the original in- jury or puncture; and in cases arising from any local irritation, no time should be lost in severing the communication with the brain and part engaged, as if to arrest the progress of this disease.

As to the use of stimulating or antispasmodic liniments or applications, I have never seen, even in extensive hospital practice, in civil or military departments, any beneficial results; I would rather be inclined to look upon them as worse than useless : for while the surgeon may be getting these ready for use, he might in my mind he much better employed in attending to more salutary and sure remedies, and to what are known to be atterded with much more efficacious and successful results, to persons who have sufered from, and had been the subjects of tetanus in any form.

\section{ON THE NERVOUS GANGLIA OF THE UTERUS.}

By Robert Lee, M.D., F.R.S.

[Published in the forthcoming volume of the Philosophical Transactions.]

THE anthor, in a paper which was read to the Royal Society on the 12th of December, 1839, had described four great plexuses under the peritoneum of the gravid uterus, having an extersive connection with the hypngastric and spermatic nerves. From their form, colour, general distribution, and resemblance to ganglionic plexuses of nerves, and from their branches actually coalescing with those of the hypogastric and spermatic nerves, he was induced to believe, on first discovering them, that they vere ganglionic nervous plexuses, and that they constituted the special nervous system of the uterus. Ge states in the present paper, thaí subsequent clissections of the unimpregnated aterus, and of the gravid uterus in the third, fourth, sixth, screnth, and ninth months of pregnancy, have enabled him not only to confirm the accuracy of his former observations, but alsu to discover the important fact, that there are many large ganglia on the uterine nerves, and on thuse of the vagina and bladder, which eniarge with the coats, blood-vessels, nerves, and absorbents of the aterns during pregnancy, and which return, after parturition, to their original condition before conception took place. The author next proceeds to describe the two great ganglia situated on the sides of the neck of the uterus, in which the hypogastric and several of the sacral nerves terminate, and which he calls the hypogrstric or utero-vesical ganglia. In the unimpreguated state, they are of an irregular, triangular, or oblong shape, about half an incis in the long diameter; and always consist of grey and white matter, like other ganglia. They are covered by the trunks of the raginal and vesical arte- 